\begin{tabular}{|c|c|}
\hline Synthetic dental bone graft firm, EthOss & experienced biomaterial product \\
\hline Regeneration Ltd, has been honoured with & development specialist, Dr Paul Harrison. \\
\hline a Queen's Award for Enterprise 2021, in & Together, the pair set out to create a \\
\hline the International Trade category. & product that would disrupt the dental bone \\
\hline The company is one of just 205 & grafting market, with the result being the \\
\hline organisations nationally to be recognised & company's flagship product - EthOss - a \\
\hline with a prestigious Queen's Award for & synthetic biomaterial used during dental \\
\hline Enterprise which celebrates outstanding & implant surgery to encourage new bone to \\
\hline achievement by UK businesses. & grow and support the implant. \\
\hline Now in its 55th year, the Queen's & Until then, this procedure had been \\
\hline Awards for Enterprise are the most & done using a material containing animal \\
\hline prestigious business awards in the country, & product - usually bone harvested from \\
\hline with winning businesses able to use the & cows, pigs and horses. The company's \\
\hline esteemed Queen's Awards emblem for the & aim is to grow a more ethical approach to \\
\hline next five years. & dental implantology worldwide. \\
\hline EthOss was set up in 2013 in West & https://www.swallowdental.co.uk/ \\
\hline Yorkshire, by world-renowned dental & dental-products/bone-graft-materials/ \\
\hline surgeon Dr Peter Fairbairn and & ethoss-bone-regeneration.html \\
\hline
\end{tabular}

\section{New eco-friendly aspirator}

Hygotip XL Bio is an environmentally friendly aspirator fitting $16 \mathrm{~mm}$ systems. It is manufactured from autoclavable biobased plastic made of sugar canes. Unlike conventional plastics where fossil raw

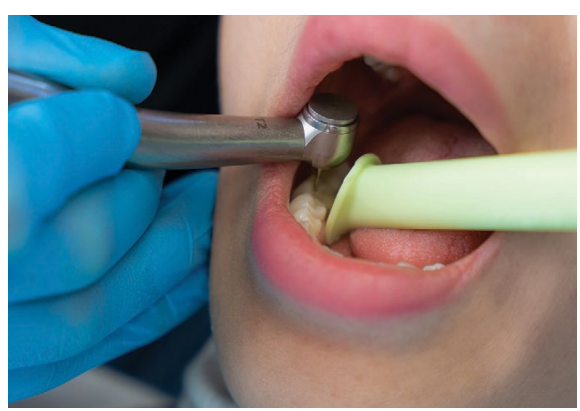

materials such as oil and natural gas are used, sugar cane is a completely renewable resource.

The large diameter of $16 \mathrm{~mm}$ gives a high suction capacity and is more efficient in absorbing aerosols near the source. The sturdy design works as a tongue holder, enabling the practitioner to retract the cheek and providing good accessibility.

The Hygotip XL Bio is very patient friendly with the specially designed ventilation grooves at the connection point of the aspirator. This prevents it from getting stuck to the soft tissue with discomfort for the patient.

For more information, visit www.orsing.se.

\section{Giving patients the 'heads up'}

Worn toothbrushes remove less plaque. With Oral-B power toothbrushes, it is a combination of the head and handle configuration, which work in perfect synergy, to give the user the ultimate clean. The small round head mimics the action used in dental prophylaxis as it gently contours each tooth.

Convincing patients to change their toothbrush head regularly is not an easy task and can be a sensitive subject. Oral-B has launched a new brush head, called CleanMaximiser, which indicates when users should buy a replacement. Following dental professional recommendation, the bristles

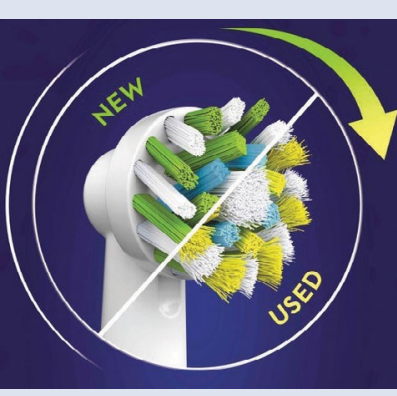
will change colour from green to yellow after three months of use, indicating it is time for a new brush head. The CleanMaximiser refills are compatible with all Oral-B models except the Pulsonic and iO.

\section{New online catalogue out now}

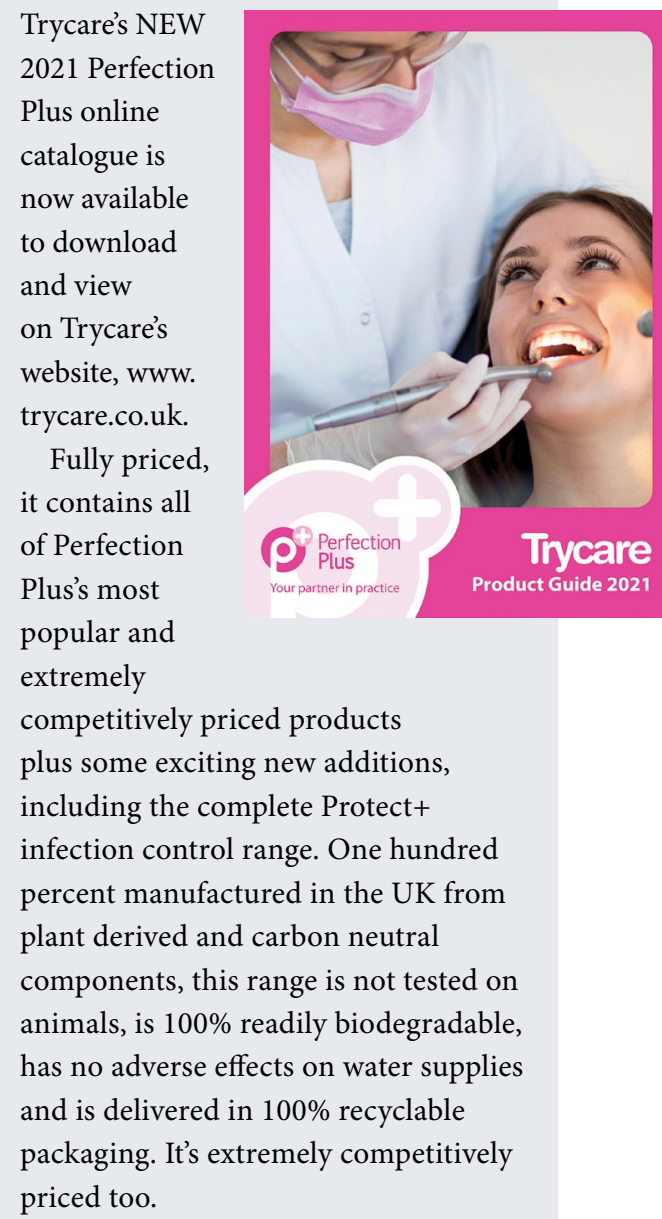

The Protect+ range includes Bio Foam Hand Sanitiser, the naturally derived, alcohol and quat-free foaming hand sanitiser, which is gentle on both your skin and the environment; Bio All Purpose Sanitiser, the environmentally responsible cleaner and disinfectant; and their Medical Face Masks Type IIR.

The Perfection Plus range covers all the everyday needs of the practice, offering a high-quality range of products you can trust, always at competitive prices.

In addition to the complete Protection Plus range, Trycare also supply everything you need from all the major dental brands as well as exclusive specialities from Adin implants, Biomin, Dr Kim, Eve Polishers, 3Dalign, Kerator, OsteoBiol, Sterisil and Tokuyama. Whatever you need, you can get it from Trycare.

For further information visit the Trycare website, www.trycare.co.uk, contact your local representative or call 01274885544. 